\title{
Study of the Possibility of Leveling the Properties of Building Heat Insulation Materials by Using of Modification Compositions
}

\author{
Marina V. ANTONOVA \\ Ph.D. (in Technical Sciences) \\ Associate Professor \\ Department of Technology of Chemical, Natural Fibers and Products \\ Kazan National Research Technological University \\ 68, Karl Marx Str., Kazan, 420015, Russia \\ marisha.10@list.ru \\ Irina V. KRASINA \\ Ph.D. (in Technical Sciences) \\ Head of the Department \\ Department of Technology of Chemical, Natural Fibers and Products \\ Kazan National Research Technological University \\ 68, Karl Marx Str., Kazan, 420015, Russia \\ irina_krasina@mail.ru
}

Svetlana V. ILYUSHINA

Ph.D. (in Technical Sciences)

Associate Professor

Department of Technology of Chemical, Natural Fibers and Products

Kazan National Research Technological University

68, Karl Marx Str., Kazan, 420015, Russia

Aleksandr S. PARSANOV

Ph.D. (in Technical Sciences)

Associate Professor

Department of Technology of Chemical, Natural Fibers and Products

Kazan National Research Technological University

68, Karl Marx Str., Kazan, 420015, Russia

thnvi@mail.ru

Alina R. IBATULLINA

Ph.D. (in Technical Sciences)

Associate Professor

Department of Technology of Chemical, Natural Fibers and Products

Kazan National Research Technological University

68, Karl Marx Str., Kazan, 420015, Russia

\section{Alina N. MINYAZOVA}

Senior Lecturer

Department of Technology of Chemical, Natural Fibers and Products

Kazan National Research Technological University

68, Karl Marx Str., Kazan, 420015, Russia

\section{Abstract}


In the work, a study of typical building heat insulation materials from plant fibers was carried out, it was revealed that these heaters along with advantages have significant drawbacks: increased combustibility and friability. The possibility of improving some operational parameters by applying modifying compositions, such as fire-protective impregnations and adhesive solutions, has been studied. Experimental studies of the influence of the selected types of modifying compositions on the properties of jute and linen fibers insulations have been carried out. Impregnations of various groups of fire-resistant efficiency were selected for the study. It was revealed that the most optimal fire-protective impregnation for the selected range of materials is "MC" flame retardant, and as an adhesive impregnation it is possible to use an aqueous polyvinyl acetate (PVA) solution. It was found that the treatment of heater insulations based on plant fibers with an aqueous solution of polyvinyl acetate (PVA) glue at a concentration of $30 \%$ is able to increase its operational properties. The conclusions of the research are presented.

Keywords: heat insulating materials; fire-resistant impregnations; polyvinyl acetate; combustibility; properties

\section{Introduction}

For the production of modern insulation, new-generation raw materials are used, which has a huge advantage over the technologies of the past. In addition, compositions and production principles are being developed for the making of low-density heat insulating fibrous materials (Babashov, Bespalov, Istomin, 2017). At the modern level of science and technology development, the application possibilities of various origin fibrous materials in the manufacture of new innovative products, including composite ones, have been significantly extended. Obtaining textile materials based on plant fibers on a symbiosis of traditional technologies with modern methods of nanostructural modification is a relevant intervention of research in the area of textile and light industry. Returning light industry to natural raw materials will allow solving a number of environmental problems. The production technologies used in recent years eliminate environmental pollution and guarantee ecological cleanliness and durability of products (URSA Russia, 2004; Medvedeva, Sekarina, 2017).

However, for the construction of certain types of buildings, such as wooden houses and bathhouses, it is necessary to use materials made of natural fibers. For insulation between logs it is impossible to use glass, stone wool and any materials based on these fibers, as well as polyurethane foam. Building insulation from natural plant components, in addition to the obvious advantages, have a number of significant disadvantages, the main of which are increased combustibility and friability during mounting. It is possible to eliminate these disadvantages using various modification methods, including modification of finished materials and products. The main requirements for choosing a modification method are the simplicity of the technology and the low cost of the technological process, in order to preserve the competitive properties of typical products (to maintain).

The work considers various approaches to the modification of non-woven materials from plant fibers used as between logs heat insulation.

Thus, the purpose of the work was to study typical building insulation materials made of plant fibers. The possibility of increasing the operational parameters of materials by applying various modifying compositions was also studied.

Various flame retardants and fire-protective impregnations can reduce the increased combustibility of plant fibers (Ilyushina, Antonova, Krasina, Minyazova, 2019; Antonova, Krasina, Ilyushina, Mingaliev, Minyazova, Ibatullina, Abdullina, 2018; Fukuta, Nomura, Nishizawa, 2014; Liodakis, Fetsis, Agiovlasitis, 2009; Wu, Shen, Hu, 2011; Pries, Mai, 2013; Kymäläinen, Sjöberg, 2008). 


\section{Methods}

The following materials were selected as research objects:

- heat insulation material from jute fibers in the form of a tape;

- linen batting.

Modification of building insulation based on natural fibers was carried out with cheap and easily accessible fire-protective impregnations and flame retardants presented on the Russian market. Flame retardants and impregnations for various purposes and groups of fire-resistant efficiency were selected as modifying compositions for the treatment of the studied insulation materials:

- fire and bio protective impregnation for wood for external and internal work named "Olimp", 2 group of fire-resistant efficiency, production Russia;

- fire and bio protective composition named "Fenilaks", 1-2 group of fire protection efficiency, TU 2389-024-13238275-03 production Russia;

- flame retardant "MC", TU 2494-002-23118566-95 water soluble, two component composition for fire-protective impregnation of textile materials, produced in Russia.

The samples were impregnated in two ways: by completely immersing the samples in a flame retardant, and by the method of surface application of flame retardants on the samples.

The fire resistance of building insulation is determined in accordance with GOST R ISO 6941. The torch was moving from reserve position, where its tip was at a distance of $75 \mathrm{~mm}$ from the sample, to horizontal working position. Samples were fixed to the rectangular frame. The elementary sample was installed so that the insulation sample was placed tightly and evenly throughout the frame. Then the holder was hanged on the frame. The torch was set perpendicularly to the sample. The flame of the torch was pointed accurately at the center of the elementary sample. After the installation was entirely ready for operation and the samples were set on their workplaces, the torch was moved to the working position and the tests were started. The test was conducted for 10 seconds. A stopwatch was used to measure the flame exposure time on the sample.

To eliminate friability, the studied materials were processed with the following composition: polyvinyl acetate (PVA) glue (GOST 18992-80) and distilled water in various concentrations.

The OLYMPUS LEXT OLS 4100 confocal laser scanning microscope ("Olympus Corporation", Japan) was used to study the structure and surface changes of textile materials.

\section{Results and Discussion}

Both standard and special research methods were used to determine the nature of the effect of various fire-protective compositions and adhesive solution on the properties of selected heat insulation materials from plant fibers.

Studies of the operational characteristics of jute and linen heat insulation were carried out before and after impregnation with various flame retardants. For testing, a test installation was used in accordance with GOST R ISO 6941.

The nature of the fire protection of the samples was estimated by the time of propagation of the flame. For this, the time was determined for which the flame spreads a certain distance along the test sample.

The results of the studies are presented in Figures 1 and 2 in the form of photographs of samples after influence to them by flame. 


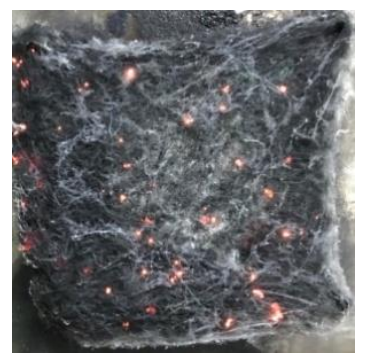

a) without flame retardant treatment

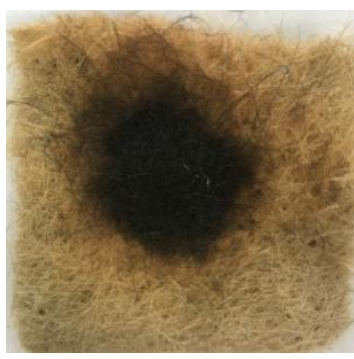

b) impregnated with flame retardant "Olimp"

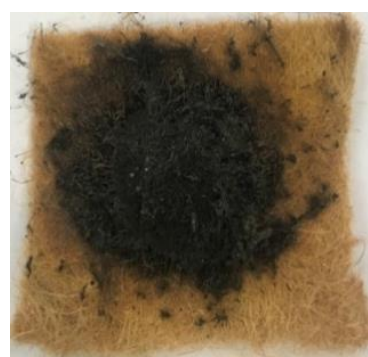

c) impregnated with flame retardant "Fenilaks"

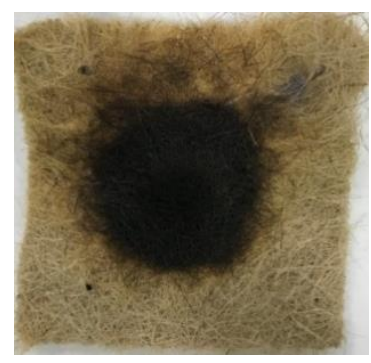

d) impregnated with flame retardant "MC"

\section{Figure 1. Samples of jute tape after influence the fire before and after impregnation with flame retardant}

Based on the results of the experiments, we can conclude that when a flame influences on an untreated jute tape, there is almost complete destruction of the test sample is observed, which can naturally lead to a fire in the building (Figure 1a). When using flame retardants, the ignition is not observed during the test time. The sample treated with "Olimp" impregnation (Figure 1b) began to darken at 11 seconds, there was no ignition. The sample treated with the "Fenilaks" impregnation (Figure 1c) began to darken at 2 seconds by exposure to flame, and to swell, there was no ignition. The sample treated with «MC» flame retardant (Fig. 1d) also began to darken at 2 seconds, at the same time smoke appeared on the back of the sample, there was no ignition.

Therefore, the using of various classes flame retardants is able of both: to exclude ignition from an accidental fire source, and to not support it for a long period of influence.

The results of experiments on the study of linen batting are presented further.

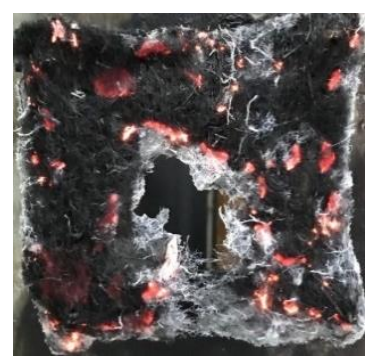

a) without flame retardant treatment

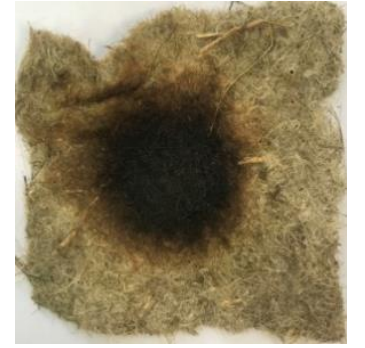

b) impregnated with flame retardant "Olimp"

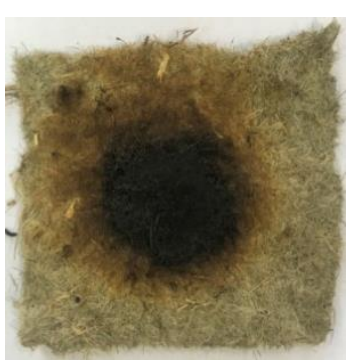

c) impregnated with flame retardant "Fenilaks"

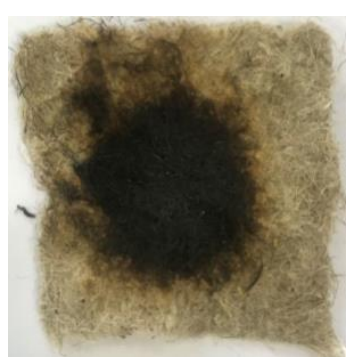

d) impregnated with flame retardant «MC»

\section{Figure 2. Samples of linen batting after influence the fire before and after impregnation with flame retardant}

Analyzing the results of the experiments presented in Figure 2, we can conclude that in a typical commercial offer of linen batting, the destruction of the test sample is observed in the first seconds of influence of the flame, which, accordingly, can lead to ignition of the entire building.

When using the selected flame retardant and fire-protective impregnations on linen batting, there was not observed the ignition of the samples at a given time of flame influence. The darkening of the samples began at 4 seconds of influence, with the appearance of smoke from the back of the samples. Samples of linen batting have preserved their integrity. There was no burnout of the 
samples after 10 seconds of exposure to the flame. A specific smell was emitted during the smoldering.

Analyzing the results presented in figures 1-2, it can be concluded that impregnation with flame retardants of various classes positively affects on the fire resistance of building heat insulations, which in turn leads to a significant increase in the fire prevention and operational properties of the studied materials.

With the introduction of additional treatments in the production of textile materials, it is necessary to take into account a change in their geometric characteristics, namely an increase in surface density. The change in the surface density of samples can be estimated by measuring the mass of the samples before and after impregnation with flame retardants.

This parameter is the values of weight gain. Identical-sized samples of insulation were made for this experiment. The same amount of flame retardant was used while impregnating the samples. The results of studies on changes in the mass of samples after impregnation with flame retardants are presented in table 1.

Table 1. Studies on changes in the mass of samples after impregnation with flame retardants

\begin{tabular}{ccc}
\hline \multirow{2}{*}{ Fire-protective impregnations } & \multicolumn{2}{c}{ The values of weight gain, \% } \\
\cline { 2 - 3 } & Jute tape & Linen batting \\
\hline "Olimp" & 43 & 38 \\
\hline "Fenilaks" & 128 & 106 \\
\hline "MC" & 37 & 35 \\
\hline
\end{tabular}

Based on the data presented in table 1, it can be seen that the minimum gain to the mass of the original (source) material is provided by impregnation of heat insulation based on plant fibers with «MC» flame retardant.

According to the results of researches for the treatment of plant fibers flame retardant MC was selected, as the most optimal.

The next important drawback of building heat insulation is their increased friability and volatility of individual fibers in the composition of the studied materials. When laying jute and linen insulation in the space between logs, part of the fibers crumble, and the heat insulation material itself becomes uneven in thickness. This drawback can be eliminated by treating the plant fiber insulations with an adhesive composition, which will lead to a relative structuring of the material as a whole. The concentration of the composition should not lead to a strong compaction of the structure and weighting of the material. In addition, the adhesive component must not be a toxic. In this study, polyvinyl acetate was selected for the treatment of heat insulation materials.

The modification of the studied samples consisted in treatment them with an aqueous polyvinyl acetate solution with a concentration of the main substance of $10 \%$ and $30 \%$.

The friability of the samples was studied under conditions close to the operational conditions of the selected material. To simulate the laying and sliding of logs, the technique of studying the surface of textile samples by abrasion method was applied.

To determine the increase in the structuring of modified building materials, an abrasive with a grit size of 60 was selected. Testing of the samples was carried out until the appearance of visible changes in the surface of the material and was evaluated by the number of revolutions of the abrasive element that the sample withstood. The samples were studied before and after polyvinyl acetate (PVA) treatment, the results of the experiments are presented in Table 2. 
Table 2. Determination of the abrasion resistance of jute tape and linen batting before and after applying the adhesive solution

\begin{tabular}{ccc}
\hline \multirow{2}{*}{ Samples } & \multicolumn{2}{c}{ The number of revolutions of the abrasive element } \\
\cline { 2 - 3 } & Jute tape & Linen batting \\
\hline Original & 1100 & 500 \\
\hline $\begin{array}{c}\text { Treated with polyvinyl acetate (PVA) at } \\
\text { a concentration of 10\% }\end{array}$ & 2800 & 500 \\
\hline $\begin{array}{c}\text { Treated with polyvinyl acetate (PVA) at } \\
\text { a concentration of 30\% }\end{array}$ & 3300 & 900 \\
\hline
\end{tabular}

Based on the data presented in table 2, we can conclude that the standard sample of jute tape withstands the minimum number of revolutions. In addition, during the test, the control sample of the jute tape showed a structure destruction and it became unsuitable for subsequent use. The samples processed with polyvinyl acetate glue showed good results in terms of strength and surface uniformity; they did not crumble and did not lose their commercial appearance. Optimal from the point of view of uniformity is the modification of the test material with an aqueous solution of polyvinyl acetate glue with a concentration of the latter $30 \%$.

The same regularity also manifests itself when linen batting is modified.

Thus, the treatment of building heat insulations based on plant fibers with an aqueous solution of polyvinyl acetate glue in a concentration of $30 \%$ can significantly increase the homogeneity of the studied materials, and, therefore, increase its operational properties. In turn, the increase in operational characteristics will lead to an increase in demand for this type of building insulation.

Since the treatment of the selected materials with the adhesive composition led to an increase in the homogeneity of the insulation, a study was conducted of the possibility of modifying the samples simultaneously with MC flame retardant and an aqueous solution of polyvinyl acetate glue with a concentration of the latter $30 \%$.

To do this, the samples were firstly impregnated with MC flame retardant, and then an adhesive composition was applied to their surface. After applying the fire-resistant and coating composition, the materials were tested according to the GOST 9913-90.

The treated samples were also tested for resistance to open flame. The results of the experiments are presented in figure 3 as a photo.

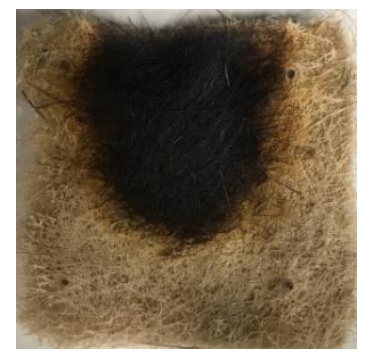

a)

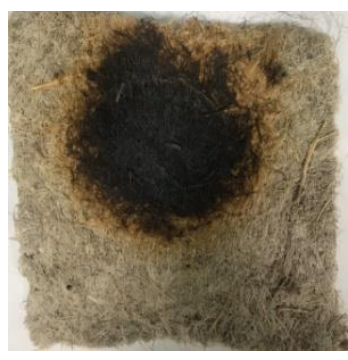

b)

Figure 3. The study on resistance to open flame of samples impregnated with «MC» flame retardant and applied polyvinyl acetate (PVA) 30\%: a) jute tape, b) linen batting

According to the results of the experiment, it was revealed that the treatment of materials with polyvinyl acetate (PVA) does not have adversely affect on the operation of the flame retardant. Ignition of samples at a given time of exposure to an open flame on its surface does not occur. The 
samples do not support combustion in the absence of flame. On the reverse side of the test materials smoke is observed.

In turn, the impregnation of insulation samples with flame retardant has a positive effect on the integrity and uniformity of the material structure as a whole. The material was tested for crumbling also by the abrasion method. Jute tape impregnated with «MC» flame retardant and applied by $30 \%$ concentration of polyvinyl acetate (PVA) withstands 3000 revolutions of the abrasive element. Linen batting impregnated with "MC" flame retardant and applied by 30\% concentration of polyvinyl acetate (PVA) withstands 1000 revolutions of the abrasive element. Comparing the results obtained with the data in figure 3 , we can conclude that the combined treatment of samples with an adhesive composition and a flame retardant has a positive effect on the properties of materials.

\section{Conclusion}

In the work a study of typical building heat insulation materials from plant fibers, such as jute tape and linen batting, was conducted.

The study identified some operational parameters that need to be improved: increased combustibility and friability of plant insulation.

The possibility of leveling weak operational parameters by applying modifying compounds has been studied. It is possible to increase the resistance of the selected insulation to the effects of open flame by using the fire-resistant impregnations. It was revealed that the most optimal fire-retardant impregnation for the selected range of materials is $\mathrm{MC}$ flame retardant. It allows you to protect the insulation from fire when exposed to an open flame, is universal in use and does not lead to a significant increase in the cost of production.

It is established that the surface treatment with adhesive compounds allows preventing the flowability of insulation materials made of plant fibers. To save the homogeneity of the heat insulation materials, it is most optimal to treat it with an aqueous polyvinyl acetate (PVA) solution at a concentration of the latter $30 \%$. In addition, it was found that the combined treatment of samples with an adhesive composition and a flame retardant does not lead to a deterioration of the properties of insulation obtained during separate processing.

\section{Contribution}

Marina Vladimirovna Antonova - main author, selection of methods and conducting the experiments;

Irina Vladimirovna Krasina - scientific consultant;

Svetlana Victorovna Ilyushina - discussion and analysis of experimental results;

Aleksandr Sergeevich Parsanov - selection of methods and conducting the experiments;

Alina Rafisovna Ibatullina - discussion and analysis of experimental results;

Alina Nikolaevna Minyazova - carrying out the literature review.

\section{References}

Antonova, M.V., Krasina, I.V., Ilyushina, S.V., Mingaliev, R.R., Minyazova, A.N., Ibatullina, A.R., Abdullina, V.H. (2018). Using of radio-frequency capacitive discharge plasma for modification of jute fabrics. Journal of Physics Conference Series, 1588, 012003.

Babashov, V.G., Bespalov, A.S., Istomin, A.V. (2017). Heat and Sound Insulation Material Prepared Using Plant Raw Material. Refractories and Industrial Ceramics, 58, 208-213. https://doi.org/10.1007/s11148-017-0082-3 
Fukuta, S., Nomura, M., Nishizawa, M. (2014). Evaluation and fireproofing treatment of wooden heat-insulating/acoustic absorbing materials. European Journal of Wood and Wood Products, 72, 713-720. https://doi.org/10.1007/s00107-014-0840-6

Ilyushina, S., Antonova, M., Krasina, I., Minyazova, A. (2019) Study of the effect of plasma modification on the change of fire-resistant properties of textile materials imported by flame retardants. Journal of Physics Conference Series, 1328, 012037.

Kymäläinen, H.R., Sjöberg, A.M. (2008). Flax and hemp fibres as raw materials for thermal insulations. Building and Environment, 43, 12611269. https://doi.org/10.1016/j.buildenv.2007.03.006

Liodakis, S., Fetsis, I.K. Agiovlasitis, I.P. (2009). The fire-retarding effect of inorganic phosphorus compounds on the combustion of cellulosic materials. Journal of Thermal Analysis and Calorimetry, 98, 285. https://doi.org/10.1007/s10973-009-0307-X

Medvedeva, G.A., Sekarina, O.S. (2017). Modern wall thermal insulation materials together with materials from waste heat power engineering. Internet journal «NAUKOVEDENIE», 9(5). Retrieved from: https://naukovedenie.ru/PDF/15TVN517.pdf

Pries, M., Mai, C. (2013). Fire resistance of wood treated with a cationic silica sol. European Journal of Wood and Wood Products, 71, 237-244. https://doi.org/10.1007/s00107-013$\underline{0674-7}$

URSA Russia. (2004). Development of modern technologies of production and application of thermal insulation materials by URSA Russia. Building materials, 1, 16-17.

Wu, K., Shen, MM., Hu, Y. (2011). Thermal degradation and intumescent flame retardation of cellulose whisker/epoxy resin composite. Journal of Thermal Analysis and Calorimetry, 104, 1083-1090. https://doi.org/10.1007/s 10973-011-1380-5 